\title{
Evaluating and Analyzing of Robotic Arm as Learning Media Based on Partial Least Square Method
}

\author{
I Gusti Putu Asto Buditjahjanto ${ }^{1}$, Pramudya Ardi ${ }^{2}$, \\ Munoto Munoto ${ }^{1}$, Muchlas Samani ${ }^{1}$ \\ ${ }^{1}$ Universitas Negeri Surabaya, Faculty of Engineering, Surabaya, Indonesia \\ ${ }^{2}$ Universitas PGRI Madiun, Madiun, Indonesia
}

\begin{abstract}
This research describes the use of a robotic arm on robot transporter as a learning media. Robot Transporter is a type of robot that can move and is equipped with a robotic arm. This robot is used to learn about the robotic arm concept which consists of the concept of arm and grip on the robot and the servo motor concept. The robotic arm concept is part of the electromechanical course at a private university in Indonesia. The purpose of this research is to analyse the relationship of the latent variables of assembling, operating and evaluating with the latent variable of psychomotor skill on the arm robotic concept. The Partial Least Square path analysis method is used to analyse and predict theoretical models of robotic arm concepts. The research results show that the latent variables of assembling, operating and evaluating have a positive influence on the psychomotor skill aspect.
\end{abstract}

Keywords - robotic arm, path analysis, Partial Least Square, Structural Equation Model, psychomotor aspect

\section{Introduction}

The development and the role of robots that have been utilized by human beings have developed rapidly.

DOI: $10.18421 /$ TEM92-33

https://doi.org/10.18421/TEM92-33

Corresponding author: I.G.P. Asto Buditjahjanto,

Department of Electrical Engineering, Faculty of Engineering, Ketintang Campus, Universitas Negeri Surabaya, Indonesia.

Email: asto@unesa.ac.id

Received: 10 March 2020.

Revised: 16 April 2020.

Accepted: 24 April 2020.

Published: 27 May 2020.

(cc)BY-NC-ND(C) 2020 I.G.P. Asto Buditjahjanto at al; published by UIKTEN. This work is licensed under the Creative Commons Attribution-NonCommercial-NoDerivs 4.0 License.

The article is published with Open Access at www.temjournal.com
One of them is the use of robots in the field of education. Many studies show that robot as a learning media can affect many aspects of education and also has a large impact on students' skills and abilities [1], [2], [3]. The use of robots in education or educational robotic has some advantages. One of the advantages is being able to attract the attention of students. According to [4], the use of educational robotics makes students more familiar and proactive in participating in programming learning to make the learning process effective. At the undergraduate level, educational robotic has been widely used in learning that helps to improve students' abilities and expertise [5], [7]. Educational robotics also has been used in helping students to better understand and encourages students to be able to learn material that is related to robotics. Some learning materials that can be used with robot as media learning include: programming learning [4], [8], [9], physics [10], science [7], [11], technology [12], [13], engineering [14], [15], and for control circuit robots and computer programming robots [16].

Another advantage of educational robotics utilization can become an effective tool for developing skills [17]. The skills required are students' creativity, collaboration and team-working, self-direction, communication skills, social and cross-cultural skills, and social responsibilities. Educational robotics is also capable to develop higher-level problem-solving skills and computational skills [18], [9]. Therefore, this research explores educational robotics in the psychomotor skills aspect. As we know the psychomotor skill aspect becomes one of the references in getting a job in the era of competence. Based on the foregoing, this research focuses on examining the psychomotor aspects of students in electro-mechanical courses that use robot learning media. This research discusses the work of arm robotic on robot transporters as learning media. This robot is one type of robot that can move and has a robotic arm. The robot transporter lecture material is part of the electromechanical subject that studies 
mechanical concepts and electronic concepts. Mechanical concept lessons are studied by learning the work of arms and grips of the robot while electronic concept lessons are studied by learning the work of electrical circuits and servo motors on the robot. Students can find out how electronic and mechanical systems work on robotic arms to be easier than just reading a textbook. Besides, lecturers can deliver electromechanical lecture material with the help of transporter robots as learning media easily. Because lecturers not only explain visually the course material, they can also explain in practice the working system of the robotic arm that is part of the lecture material.

The purpose of this research is to analyze the relationship of the latent variables of assembling, operating and evaluating with the latent variable of psychomotor skill on the arm robotic concept. Therefore, the major research hypotheses are as follows:

$\mathrm{H} 1$ : Assembling the robotic arm on the transporter robot positively influences the psychomotor aspect of the student.

$\mathrm{H} 2$ : Operating the robotic arm on the transporter robot positively influences the psychomotor aspect of the student.

H3: Evaluating the robotic arm on the transporter robot positively influences the psychomotor aspect of the student.

This research used Partial Least Squares (PLS). PLS is an SEM technique that employs a componentbased approach to explaining and predicting a theoretical model that was built [19], [20]. According to [21], that PLS is an exploratory technique that uses the data to test the relationship among latent variables and to analyse the path relationships in models. So, it can help researchers to find out the relationship among sets of observed variables. This research builds a model with several latent variables (constructs). The constructs are assembling, operating, evaluating and psychomotor skills.

\section{Materials}

\subsection{Educational Robotics}

The use of robotics in education is a challenge for teachers to develop their curriculum following the trend of utilizing robotics in education [22], in line with the research of [15] that teaching and learning using educational robotics can be used in the classroom. Reference [23] states that learning using robotics media can be used in the teaching-learning process, where the use of this robot will lead to an understanding of how teachers are involved, learn about, and use robotics to teach. Robot in education can be used to study mechanical and electrical concepts, computer programming, principles of electrical engineering [26], communications, control, mechatronics, and microcontrollers [27].

Robotic learning media can also train or instill students' soft skills such as problem-solving skills, computational thinking skills, student creativity, and students' engagement [13]. According to [9], educational robotics in the classroom of early childhood can foster programming skills and computational thinking. This is supported by the research results of [28] and [29] which state that the robot instructional kit developed can help develop the creativity of students. In educational robotics competitions, robotic learning media can also be used to teach the problem-solving strategies of participating teams and their influence on the teams. According to [30], that educational robotics can be used to learn the conceptual, algorithmic, constructional and implementation aspects of building competitive robots.

\subsection{Educational Robotics Types}

At present, the types of robotic learning media that have been used to assist in learning are many kinds. Educational robotic as learning media can be in the form of robot kits [5], simulation robots in the form of Intelligent Tutorial Systems [31] and robot trainers [28].

Robot kits in the form of robotics construction kits (RCKs) can be used in P-12 learning in the STEM disciplines. Reference [12] used RCKs in their research. The research result shows that robotics learning progression can yield gains in the course of engineering design and programming. Besides, robot kits such as Lego Mindstorms have been widely used in learning material. This robot kit can facilitate students in learning STEAM (science, technology, engineering, arts, and mathematics) skills such as a simple mechanical structure of robots that can carry out complicated work [5]. Robot kits can also be used to develop higher-level problem-solving skills [14] and [18].

Robots in the form of robot trainers have also been widely used in learning. Reference [28] used an fpalette kit based on a microcomputer to become a learning medium for learning programming on robots. The robot trainer in the form of a modular reconfigurable robot, The DoF-Box, was used as Hands-on practical of robotics taught to microengineering students. With a modular concept, Robot trainers present the software and hardware of the robots. This Robot trainer can explain the pedagogical approach that was adopted in the form of practical [29]. 


\section{Robot Transporter}

This research used a transporter robot that is a mobile robot that is driven by a wheel and has an arm and gripper to pick up an object. The robotic arm on the robot transporter is one of the main topics of electromechanical courses taught at an Electrical Engineering Department at a private university in Indonesia.

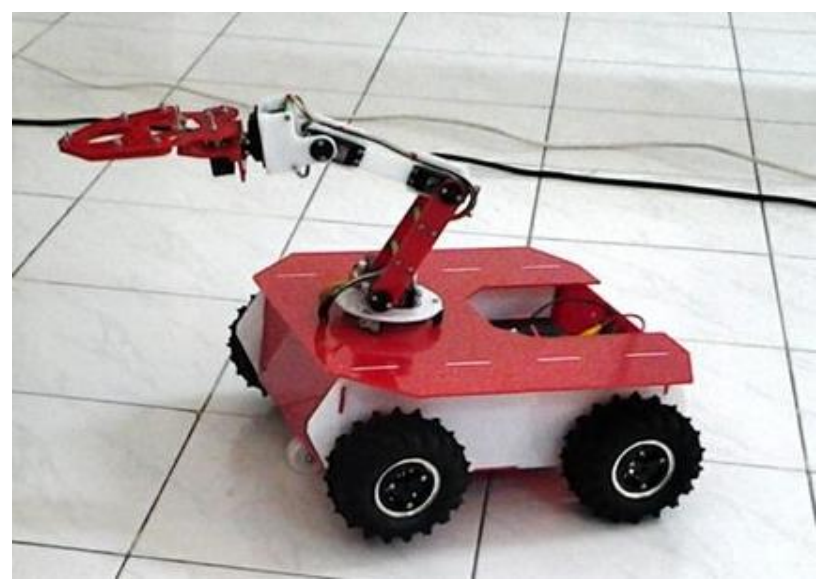

Figure 1. Robot transporter with robotic arm

Figure 1. shows the robot transporter developed in this research. This robot transporter consists of a robot arm part, a mobile part, and a controller part. This research investigated the students' learning outcome in the psychomotor skill aspect delivered in teaching and learning activities that are focused on the robotic arm. The learning process of the robotic arm was carried out on laboratory program activity. The developed students' psychomotor aspects are in the form of constructs such as assembling, operating and evaluating the robotic arm. These constructs are important to develop for students to understand and become capable of mastering the laboratory program activity on the robotic arm. Therefore, the students' psychomotor aspects have a big role in this activity.

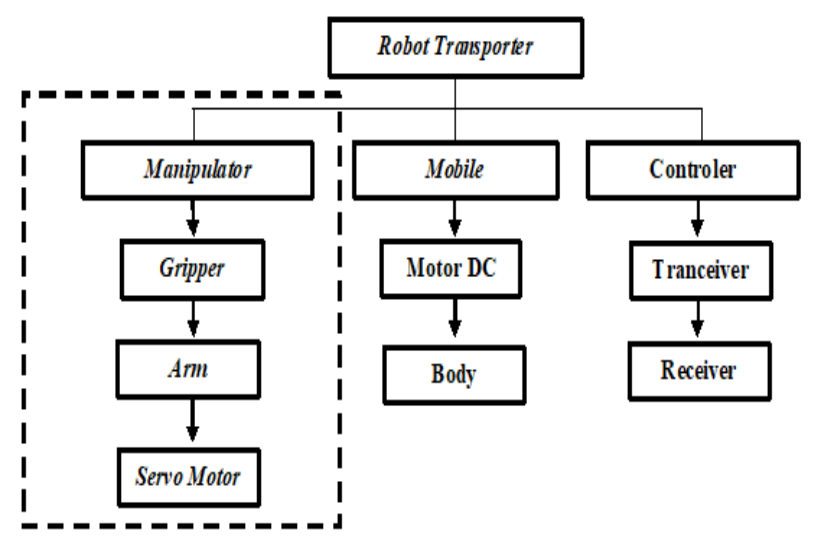

Figure 2. Concept map of a robot transporter

The concept map of learning materials for transporter robots is as shown in Figure 2. The concept map of learning materials consists of 1) robot arms parts consist of manipulators, grippers, arms, and servo motors, 2) mobile parts consist of a DC motor that drives the 4 wheels of robot transporter and the body of the robot transporter, 3) controller parts consist of transceiver and receiver. The dashed line is the section of robotic arm learning material that was used for this research.

\section{Research Model}

This research develops and tests a model of the relationship between exogenous variables consisting of assembling, operating, and evaluating against the endogenous variable of psychomotor skill. This developed model is a discussion material of the robotic arm on the robot transporter subpart of the electromechanical course. Electromechanical subjects emphasize more on laboratory program activity so that psychomotor aspects are more often used. The relationship model between constructs is shown in Figure 3.

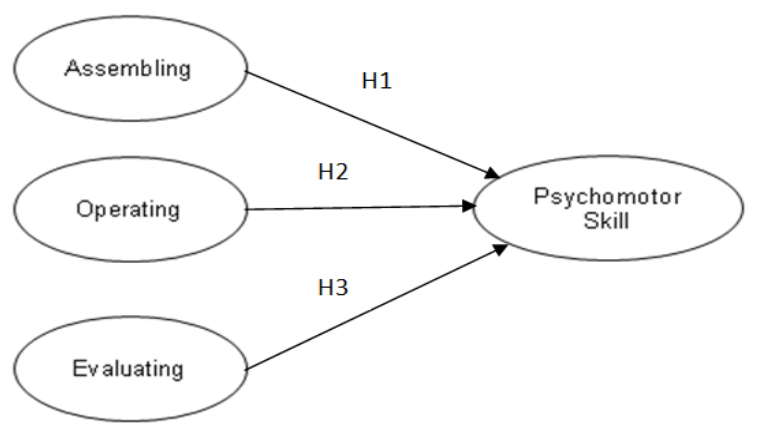

Figure 3. The relationship of development model

\section{a. Procedure}

The laboratory program consists of a lecture and works in each week as follows:

Week 1: Components of robot transporter

- Lecture: Explain the function of the components that make up the robotic arm system on the robot transporter.

- Work: Students identify each component of the robotic arm system such as manipulators, gripers, arms, joints, links and servo motors. Students explain each of the functions of manipulators, gripers, arms, joints, links and servo motors.

Week 2: Assembling robotic arm systems in joint and link parts.

- Lecture: Explain and demonstrate how to assemble robotic arm components consisting of a joint and a link.

- Work: Students describe robotic arm components and their information. Students assemble robotic arm components consisting of a joint and a link. 


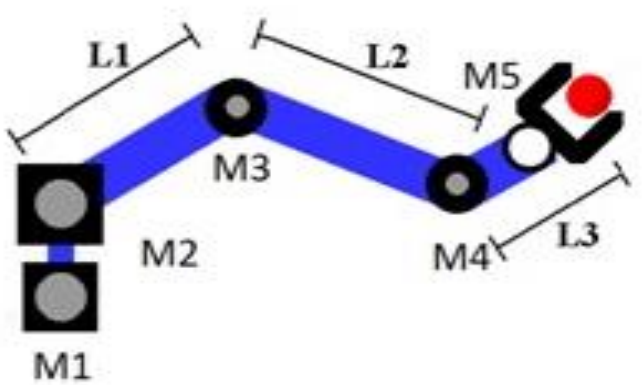

Figure 4. Robotic arm with a joint and a link

Week 3: Assembling the gripper

- Lecture: Explain and demonstrate how to assemble a gripper.

- Work: Students describe the gripper mechanism and their information. Students assemble the gripper which is part of the robotic arm.

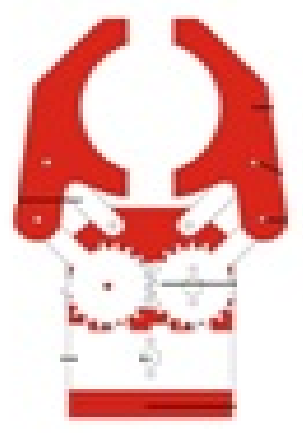

Figure 5. Gripper robot

Week 4: Assembling and operating the servo motor to move the robotic arm.

- Lecture: Demonstrating how to install each servo motor (M1, M2, M3, M4, M5, M6 and M7) on the robotic arm.

- Work: Students can connect the robot's electrical circuit to the battery. Students are capable to determine the input cable, signal, and output on the servo motor. Students explain the function of each servo motor movement (M1, M2, M3, M4, M5, M6, and M7) on the robotic arm. Students install servo motors on robotic arms.

Week 5: Operating and testing of robotic arm systems.

- Lecture: Demonstrate all robot arm movements that have been connected to the Android mobile via Bluetooth.

- Work: To move the robot arm, the remote control is used on an Android phone that has been programmed with the Remote Transporter application; scan the Bluetooth address of the transporter robot. After the Bluetooth address is connected, turn on the Servo Motor switch. By pressing the command button on the mobile screen, the robot arm can work.

- Students test the movement of the robot arm to move forward. Students test the robot arm's movements to move backward. Students test the rotating arm shaft to the right. Students test the rotating arm shaft to the left. Students test the rotating gripper shaft to the right. Students test the gripper shaft turning left. Students test gripper pinching the object. Students test the gripper taking off the object.

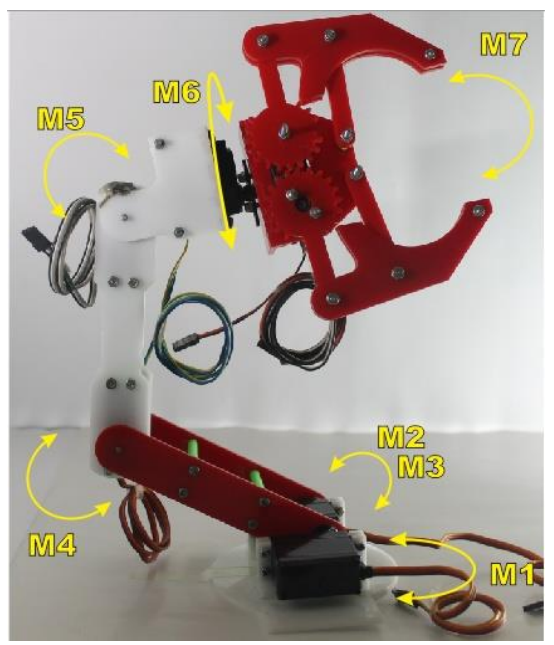

Figure 6. Servo motor movement on the robotic arm

Week 6: Repairing and evaluating of the robotic arm system.

- Lecture: Identify and demonstrate how to repair the damage that commonly occurs in the robotic arm.

- Work: students identify and repair the damage of the arm if it does not work properly. Students repair the gripper if the mechanical system does not work properly. Students identify and correct joint if it does not work properly. Students identify and correct link if it does not work properly. Students identify and repair servo motor if it does not work properly.

Week 7: Presentation of the robotic arm system.

- Lecture: Provide a review of the students' presentations.

- Work: students present their work on the build of the robotic arm and explain the problems encountered during the assembly of the robotic arm on the robot transporter.

\section{b. Participants}

Participants in this research are 40 undergraduate students of electrical engineering in a private university in Indonesia. All undergraduate students take electromechanical subjects. 


\section{c. Instruments development}

This research developed the instrument to measure latent variables such are assembling, operating and evaluating. Several indicators are needed to define the latent variables. All indicators of latent variables in the model were measured using a 5-point Likert scale.

\section{Data Analysis}

One of the advantages of the PLS, according to [32], is that PLS can be used to analyse all of the paths in one analysis. Therefore, we used the path analysis of the PLS to analyse the relationship between independent variables (assembling, operating and evaluating) toward dependent variables (psychomotor skills). Moreover, the PLS works efficiently with complex models and small sample sizes [33], [24]. As mentioned before, our research only used 40 participants (small sample sizes).

The software application used to analyse data was the XLSTAT, a PLS computer application, to evaluate the relationship between inter-constructs and also the relationship between constructs and indicators. Figure 7. shows the results of running the XLSTAT program from the relationship model of the assembling, operating and evaluating constructs of psychomotor skills.

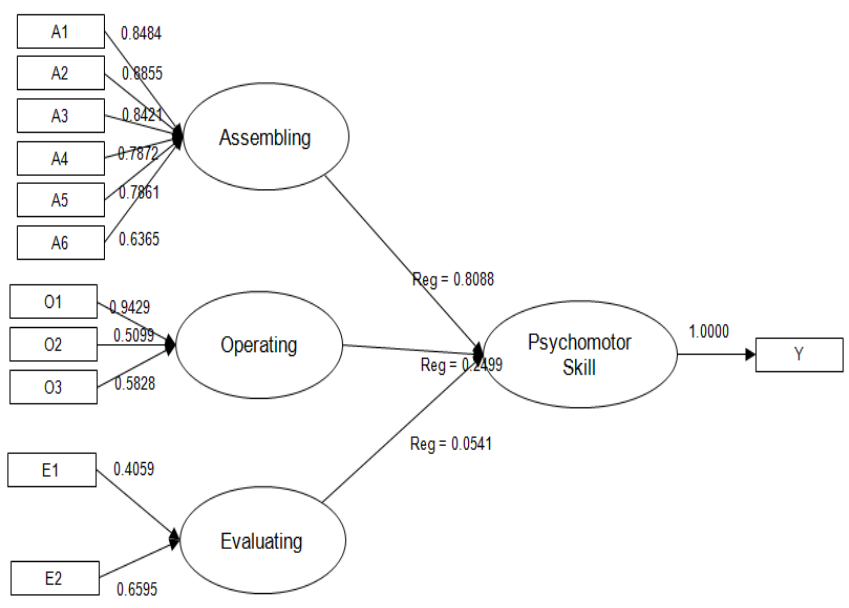

Figure 7. The simulation results of the relationship model

Table 1. shows the indicator descriptions and the simulation results of the XLSTAT program for the loading factor.

The test of the structural model includes estimates of the path coefficients $(\beta)$, which indicate the strengths of the relationships between the dependent, and independent variables, and the coefficient of determination, $\left(\mathrm{R}^{2}\right)$ values, which represent the amount of variance explained by the independent variables. Together, the coefficient of determination and the path coefficients indicate how well the data supports the hypothesized model.
Table 1. The indicator descriptions and loading factor

\begin{tabular}{|c|c|c|c|}
\hline Construct & 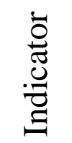 & Indicator description & $\begin{array}{c}\text { Loading } \\
\text { Factor }\end{array}$ \\
\hline \multirow{6}{*}{ Assembling } & A1 & $\begin{array}{l}\text { Capable to select } \\
\text { components according } \\
\text { to laboratory projects. }\end{array}$ & 0.8484 \\
\hline & A2 & $\begin{array}{l}\text { Capable to connect } \\
\text { the robot's electrical } \\
\text { circuit to the battery. }\end{array}$ & 0.8855 \\
\hline & A3 & $\begin{array}{l}\text { Capable to determine } \\
\text { the input cable, signal, } \\
\text { and output on the } \\
\text { servo motor. }\end{array}$ & 0.8421 \\
\hline & A4 & $\begin{array}{l}\text { Capable to install the } \\
\text { robot arm components } \\
\text { in its place. }\end{array}$ & 0.7872 \\
\hline & A5 & $\begin{array}{l}\text { Capable to install the } \\
\text { robot gripper } \\
\text { components in its } \\
\text { place. }\end{array}$ & 0.7861 \\
\hline & A6 & $\begin{array}{l}\text { Capable to assemble } \\
\text { all components of the } \\
\text { robot perfectly. }\end{array}$ & 0.6365 \\
\hline \multirow{3}{*}{ Operating } & $\mathrm{O} 1$ & $\begin{array}{l}\text { Capable to operate the } \\
\text { robot following the } \\
\text { safety standards. }\end{array}$ & 0.9429 \\
\hline & $\mathrm{O} 2$ & $\begin{array}{l}\text { Capable to operate the } \\
\text { robot following the } \\
\text { standards of specified } \\
\text { time. }\end{array}$ & 0.5099 \\
\hline & $\mathrm{O} 3$ & $\begin{array}{l}\text { Capable to operate } \\
\text { arm and gripper of the } \\
\text { robot according to } \\
\text { operating standards. }\end{array}$ & 0.5828 \\
\hline \multirow[b]{2}{*}{ Evaluating } & E1 & $\begin{array}{l}\text { Capable to assemble } \\
\text { the robot according to } \\
\text { laboratory projects. }\end{array}$ & 0.4059 \\
\hline & E2 & $\begin{array}{l}\text { Capable to analyse the } \\
\text { functions of the arm } \\
\text { and gripper of the } \\
\text { robot. }\end{array}$ & 0.6595 \\
\hline $\begin{array}{l}\text { Psychomotor } \\
\text { Skill }\end{array}$ & $\mathrm{Y}$ & $\begin{array}{l}\text { Performance test } \\
\text { result. }\end{array}$ & 1.0000 \\
\hline
\end{tabular}

Table 2. Path coefficients of latent variables

\begin{tabular}{|c|c|c|c|c|}
\hline & Value & Standard error & $\mathrm{t}$ & $\operatorname{Pr}>|\mathrm{t}|$ \\
\hline Assembling & 0.8088 & 0.0179 & 45.2690 & 0.0000 \\
\hline Operating & 0.2499 & 0.0169 & 14.8112 & 0.0000 \\
\hline Evaluating & 0.0541 & 0.0151 & 3.5846 & 0.0010 \\
\hline
\end{tabular}

Table 2. shows the simulation results of the developed model which consists of path coefficient, standard error, t-value. Furthermore, the results of this simulation are used to answer the research hypotheses. Table 3. shows the relationship between Hypothesized Path values supported or not supported based on $\beta$ values, and $t$-values. 
Tabel 3. Hypothesized Path

\begin{tabular}{|c|l|c|c|c|}
\hline $\begin{array}{c}\text { Hypot } \\
\text { hesis }\end{array}$ & $\begin{array}{c}\text { Hypothesized } \\
\text { Path }\end{array}$ & $\beta$ & $\mathrm{t}$-value & Result \\
\hline H1 & $\begin{array}{l}\text { Assemblin } \rightarrow \\
\text { Psychomotor } \\
\text { Skill }\end{array}$ & 0.8088 & $\begin{array}{c}45.2690 \\
*\end{array}$ & Supported \\
\hline H2 & $\begin{array}{l}\text { Operating } \rightarrow \\
\text { Psychomotor } \\
\text { Skill }\end{array}$ & 0.2499 & $\begin{array}{c}14.8112 \\
*\end{array}$ & Supported \\
\hline H3 & $\begin{array}{l}\text { Evaluating } \rightarrow \\
\text { Psychomotor } \\
\text { Skill }\end{array}$ & 0.0541 & $3.5846^{*}$ & Supported \\
\hline
\end{tabular}

*The critical t-value is 1.65 for a significance level of $10 \%$, 1.96 for a significance level of $5 \%, 2.58$ for a significance level of $1 \%$ (all two-tailed).

Simulation results show that Hypothesis 1: Assembling robot transporter positively influences the psychomotor aspect of the student is supported, because the simulation results show the value of $\beta=$ 0.8088 and $\mathrm{t}$-value $=45.2690$. By using a significant value of 0.05 , the t-table value is 1.96 then the hypothesis is supported. Hypothesis 2: Operating robot transporter positively influences the psychomotor aspect of the student is supported, because the simulation result shows that $\beta=0.2499$ and $\mathrm{t}$-value $=14.8112$. Where the simulation uses a significant value of 0.05 with a t-table value of 1.96 , the hypothesis is supported. Finally, Hypothesis 3: Evaluating the robot transporter positively influences the psychomotor aspects of the student is supported, because the simulation results show that it produces $\beta$ $=0.0541$ and $\mathrm{t}$-value $=3.5846$. Where the simulation uses a significant value of 0.05 with a t-table value of 1.96 , the hypothesis is supported.

Tabel 4. Coefficient Determination $\left(R^{2}\right)$ of Model

\begin{tabular}{|c|c|c|c|c|}
\hline $\mathrm{R}^{2}$ & $\mathrm{~F}$ & $\operatorname{Pr}>\mathrm{F}$ & $\mathrm{R}^{2}$ (Bootstrap) & $\begin{array}{c}\text { Standard } \\
\text { error }\end{array}$ \\
\hline 0.9931 & 1734.1573 & 0.0000 & 0.9898 & 0.0052 \\
\hline
\end{tabular}

From the simulation result, as seen in Table 4., Psychomotor Skill is found to be significantly determined by the three exogenous variables (Assembling, Operating \& Evaluating), resulting in an $R^{2}$ of 0.9931 . This means that the above exogenous variables explain 98\% of the variance in Psychomotor Skill.

\section{Discussion}

Simulation results show that the Assembling, Operating, and Evaluating variables have a positive influence and significant contribution to the psychomotor skill variable. Figure 8 . shows the impact and contribution of the variables on psychomotor skills. Assembling gave the biggest impact and contribution, namely 0.8088 , followed by Operating, giving an impact and contribution of 0.2499 and finally, Evaluating gave an impact and contribution of 0.0541 .

The latent variable of assembling gives a major contribution. It is following the material on electromechanical course emphasis on psychomotor aspects so that it automatically contributes greatly. Operating skills are also trained in this course by making moderate contributions. As for evaluating abilities that tend to use cognitive make a small contribution, so if formulated it would be as follows:

Psychomotor Skill $=0.8088 *$ Assembling +0.2499

* Operating $+0.0541 *$ Evaluating

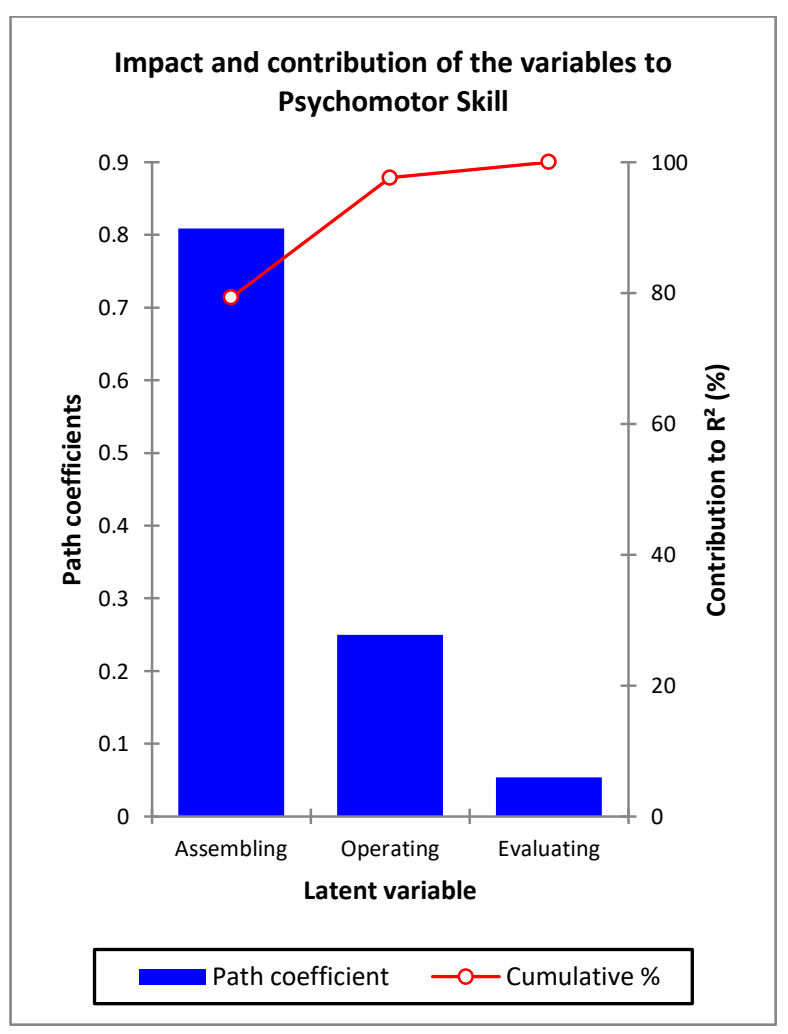

Figure 8. Impact and contribution of the variables to psychomotor skill

The $\mathrm{R}^{2}$ shows the fraction of total variance in the dependent variable accounted for by those independent [25]. Therefore, the bigger the $\mathrm{R}^{2}$, the more the predictive power of the model that developed [6]. On the whole, a substantial amount of variance is explained in the dependent variable, the psychomotor skill. According to [33] if the $\mathrm{R}^{2}$ value of endogenous latent variables of $>0.75$, so it is categorized as substantial. The simulation result shows that the $R^{2}$ value is 0.9931 , indicates that a substantial proportion of variance of the psychomotor skill predicted by those three independent variables, Assembling, Operating, Evaluating, is substantial. 


\section{Conclusion}

The results of this research indicate that each of the latent variables, such as assembling, operating and evaluating, can make a significant contribution to students' psychomotor skills. Each of the latent variables contributes to the psychomotor skill. The contribution of Assembling variable is $\beta=0.8088$, Operating variable contribution is $\beta=0.2499$, and Evaluating variable contribution is $\beta=0.0541$. So, it can be concluded that Assembling, Operating, and Evaluating can make a significant contribution to students' psychomotor skills.

The results of this research were able to answer all three hypotheses. Hypothesis 1 (Assembling $\rightarrow$ Psychomotor Skill) is supported with the value of $t-$ value $=45.2690$ and $\rho$-value $<0.001$, Hypothesis 2 (Operating $\rightarrow$ Psychomotor Skill) is supported with the value of $\mathrm{t}$-value $=14.8112$ and $\rho$-value $<0.001$ and Hypothesis 3 (Evaluating) $\rightarrow$ Psychomotor Skill) is supported by the value of $\mathrm{t}$-value $=3.5846$ and $\rho$ value $<0.001$.

\section{References}

[1]. Tetsuya Akagi, Shinsaku Fujimoto, Hiroaki Kuno, Keisuke Araki, Satoshi Yamada, Shujiro Dohta. (2015). Systematic Educational Program for Robotics and Mechatronics Engineering in OUS Using Robot Competition. Procedia Computer Science, 76, 2-8.

[2]. Scaradozzi, D., Screpanti, L., \& Cesaretti, L. (2019). Towards a definition of educational robotics: a classification of tools, experiences and assessments. In Smart Learning with Educational Robotics (pp. 6392). Springer, Cham.

[3]. Athanasiou, L., Mikropoulos, T. A., \& Mavridis, D. (2018, June). Robotics Interventions for Improving Educational Outcomes-A Meta-analysis. In International Conference on Technology and Innovation in Learning, Teaching and Education (pp. 91-102). Springer, Cham.

[4]. Ohnishi, Y., Honda, K., Nishioka, R., Mori, S., \& Kawada, K. (2017). Robotics Programming Learning for Elementary and Junior High School Students. Journal of Robotics and Mechatronics, 29(6), 992-998.

[5]. Fukui, R., \& Sato, T. (2011). Educational Activities with a Focus on Robot Strategies-Through the Development of LEGO Manipulation Robots. Journal of Robotics and Mechatronics, 23(5), 759.

[6]. Weinfurt, K. P. (1995). Multivariate analysis of variance. In L. G. Grimm \& P. R. Yarnold (Eds.), Reading and understanding multivariate statistics (p. 245-276). American Psychological Association.

[7]. Kim, C., Kim, D., Yuan, J., Hill, R. B., Doshi, P., \& Thai, C. N. (2015). Robotics to promote elementary education pre-service teachers' STEM engagement, learning, and teaching. Computers \& Education, 91, 14-31.
[8]. Bacca-Cortés, B., Florián-Gaviria, B., García, S., \& Rueda, S. (2017). Development of a platform for teaching basic programming using mobile robots. Revista Facultad de Ingeniería, 26(45), 61-70.

[9]. Caballero González Y. A. and A. García-Valcárcel Muñoz-Repiso. (2018, October). A robotics-based approach to foster programming skills and computational thinking: Pilot experience in the classroom of early childhood education. In Proceedings of the 6th International Conference on Technological Ecosystems for Enhancing Multiculturality (TEEM 2018) (Salamanca, Spain, October 24-26, 2018), F. J. García-Peñalvo Ed. ACM, New York, NY, USA, 5 pages.

[10]. Orlando, S., Gaudioso, E., \& de la Paz, F. (2018, April). IDEE: A Visual Programming Environment to Teach Physics Through Robotics in Secondary Schools. In International Conference on Robotics and Education RiE 2017 (pp. 241-246). Springer, Cham.

[11]. Barak, M., \& Assal, M. (2018). Robotics and STEM learning: Students' achievements in assignments according to the P3 Task Taxonomy-practice, problem solving, and projects. International Journal of Technology and Design Education, 28(1), 121-144.

[12]. Sullivan, Florence \& Heffernan, John. (2016). Robotic Construction Kits as Computational Manipulatives for Learning in the STEM Disciplines. Journal of Research on Technology in Education, 48, $1-24$.

[13]. Chookaew, S., Howimanporn, S., Pratumsuwan, P., Hutamarn, S., Sootkaneung, W., \& Wongwatkit, C. (2018, July). Enhancing High-School Students' Computational Thinking with Educational Robotics Learning. In 2018 7th International Congress on Advanced Applied Informatics (IIAI-AAI) (pp. 204208). IEEE.

[14]. Arís, N., \& Orcos, L. (2019). Educational robotics in the stage of secondary education: empirical study on motivation and STEM skills. Education Sciences, 9(2), 73.

[15]. Breuch, B., \& Fislake, M. (2018, April). Bringing Educational Robotics into the Classroom. In International Conference on Robotics and Education RiE 2017 (pp. 101-112). Springer, Cham.

[16]. De Cristóforis, P., Pedre, S., Nitsche, M., Fischer, T., Pessacg, F., \& Di Pietro, C. (2013). A BehaviorBased Approach for Educational Robotics Activities. IEEE transactions on education, 56, 61-66.

[17]. Ahmad Khanlari. (2013). Effects of robotics on 21st century skills. European Scientific Journal, 9(27), 2636.

[18]. Altin, H., Pedaste, M., \& Aabloo, A. (2010). Robotics in education: Methods of getting schools involved in robotics project in Estonia. In International Conference on Simulation, Modeling and Programming for Autonomous Robots (pp. 1516).

[19]. Ravand, H., \& Baghaei, P. (2016). Partial least squares structural equation modeling with $\mathrm{R}$. Practical Assessment, Research \& Evaluation, 21(11), $1-16$. 
[20]. Rönkkö, M., \& Evermann, J. (2013). A critical examination of common beliefs about partial least squares path modeling. Organizational Research Methods, 16(3), 425-448.

[21]. Hair, J. F., Ringle, C. M., \& Sarstedt, M. (2011). PLS-SEM: Indeed a silver bullet. Journal of Marketing theory and Practice, 19(2), 139-152.

[22]. Maximova, M., \& Kim, Y. (2016). Research Trend Analysis on the Usage of Robotics in Education. AsiaPacific Collaborative education Journal, 12(1), 4560.

[23]. Gorakhnath, Igona \& Padmanabhan, Jubilee. (2017). Educational Robotics in Teaching Learning Process. Online International Interdisciplinary Research Journal, 7(02).

[24]. Rezaei, S., \& Ghodsi, S. S. (2014). Does value matters in playing online game? An empirical study among massively multiplayer online role-playing games (MMORPGs). Computers in Human Behavior, $35,252-266$.

[25]. Jasimuddin, S. M., Mishra, N., \& A. Saif Almuraqab, N. (2017). Modelling the factors that influence the acceptance of digital technologies in egovernment services in the UAE: a PLS-SEM Approach. Production Planning \& Control, 28(16), 1307-1317.

[26]. Rahnavard, M., Alavi, S. M. H., Khorasani, S., Vakilian, M., \& Fardmanesh, M. (2018). Educational robot for principles of electrical engineering. Scientia Iranica, 25(3), 1582-1592.
[27]. Garduño-Aparicio, M., Rodríguez-Reséndiz, J., Macias-Bobadilla, G., \& Thenozhi, S. (2018). A Multidisciplinary Industrial Robot Approach for Teaching Mechatronics-Related Courses. IEEE Transactions on Education, 61(1), 55-62.

[28]. Okumura, Y. (2011). Developed Educational Robotics Instruction Kit For Embody Creativity" fpalette" Educational Microcomputer Kit with Extension Methods and Full JTAG Function. J. of Robotics and Mechatronics, 23(5), 618-628.

[29]. Daidié, D., Barbey, O., Guignard, A., Roussy, D., Guenter, F., Ijspeert, A., \& Billard, A. (2007, September). The dof-box project: An educational kit for configurable robots. In 2007 IEEE/ASME international conference on advanced intelligent mechatronics (pp. 1-6). IEEE.

[30]. Pöhner, N., \& Hennecke, M. (2018, October). Learning problem solving through educational robotics competitions: first results of an exploratory case study. In Proceedings of the 13th Workshop in Primary and Secondary Computing Education (pp. 46).

[31]. Fournier-Viger, P., Nkambou, R., Nguifo, E. M., Mayers, A., \& Faghihi, U. (2013). A multiparadigm intelligent tutoring system for robotic arm training. IEEE Transactions on Learning Technologies, 6(4), 364-377.

[32]. Komiak, S. Y. X., and I. Benbasat. (2006). The Effects of Personalization and Familiarity on Trust in and Adoption of Recommendation Agents. Management Information Systems Quarterly, 30(4), 941-960.

[33]. Hair Jr, J. F., Hult, G. T. M., Ringle, C., \& Sarstedt, M. (2016). A primer on partial least squares structural equation modeling (PLS-SEM). Sage publications. 